\title{
Using Educative Curriculum Materials to Support Preservice Elementary Teachers' Curricular Planning: A Comparison Between Two Different Forms of Support
}

\author{
CARRIE J. BEYER \\ ELIZABETH A. DAVIS \\ University of Michigan \\ Ann Arbor, MI, USA
}

\begin{abstract}
Educative curriculum materials-materials designed to promote both teacher and student learning-may help novice teachers learn how to engage in productive curricular planning. However, little is known about how educative supports within these materials should be written to best support teachers. This quasi-experimental study examines the affordances and constraints of two different forms of educative support, general supports and lesson-specific supports, in helping preservice elementary teachers critique and adapt science curriculum materials. The lessonspecific narrative supports helped the preservice teachers identify specific adaptations that they could make to lesson plans. They also led the preservice teachers to view the educative supports as useful and relevant, motivating them to use the supports in their analysis. In contrast, the general expository supports helped the preservice teachers identify principles of practice to use in their analysis of lesson plans. Implications for teacher education and curriculum materials design are discussed, including the need to provide a blend of both forms of support to help teachers make productive design decisions when planning with curriculum materials.
\end{abstract}

Curriculum materials are intimately connected to the daily work of teachers. Teachers use these written resources to help them make thoughtful decisions about classroom practice. For example, teachers often use curriculum materials to address district- and state-level curriculum frameworks, which define what students need to know and be able to do as a result of instruction (Remillard, 2005). Because curriculum materials specify what and how to teach, teachers use these curricular tools to

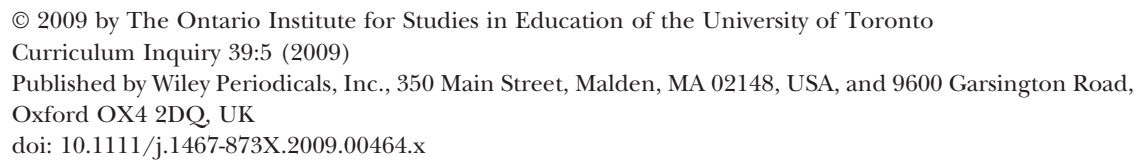


guide their planning and enactment of lessons (Ball \& Cohen, 1996; Remillard, 2005; Shulman, 1986). Even more, teachers teaching outside their content area and those entering the field of teaching tend to rely extensively on such materials for instruction (Grossman \& Thompson, 2004; Mulholland \& Wallace, 2005; Powell, 1997). For these reasons, curriculum materials play a central role in the everyday work of teachers.

In addition to helping teachers plan and enact instruction, some curriculum materials are also designed to support teacher learning (Ball \& Cohen, 1996; Schneider \& Krajcik, 2002). Materials intended to be educative for teachers, in addition for students, have been termed educative curriculum materials (Davis \& Krajcik, 2005). Educative curriculum materials do not simply prescribe what and how to teach but also engage teachers in "the ideas underlying the writers' decisions and suggestions" (Remillard, 2000, p. 347). They can help teachers make productive and informed decisions about how to design instruction for their students. They can also help teachers learn in and from their work by developing their knowledge and beliefs about content and learners and expanding their repertoire of instructional practices (Collopy, 2003; Schneider \& Krajcik, 2002).

Even though curriculum materials can be designed with the intention of promoting teacher learning, little is known about how educative supports should be written to best support teachers. To address this gap in the literature, we examine two different forms of educative support (general versus lesson specific) and their potential for promoting teacher learning. Specifically, we applied a quasi-experimental design to two sections of an elementary science methods course, providing each section with a different form of support to assist them in their analysis of science lesson plans. We examined how the preservice teachers used the different forms of support, what their views were on their usefulness, and how the different forms of support impacted their ability to apply what they had learned in their analysis of lesson plans. Thus, the nature of our research questions focused not only on developing descriptions about how the preservice teachers used and viewed the educative supports but also on establishing causal inferences about the effect of the different forms of support on the preservice teachers' ability to analyze lesson plans, thereby leading us to use a quasi-experimental approach in our study design (National Research Council [NRC], 2002). In addition, pragmatically, we were afforded the opportunity to have the same instructor teach both sections of the course, which enabled us to have parallel activities and assignments between the two course sections while providing each group with a different form of support. Finally, while the study takes place with preservice teachers, we argue that the results have implications for the design of educative curriculum materials, more generally. 


\section{THEORETICAL FRAMEWORK}

This study is grounded in the theoretical perspective that teachers and curriculum materials participate together in a dynamic, collaborative relationship (Brown, 2009; Remillard, 2005). In contrast to other perspectives that view teachers as mere conduits of curriculum materials (e.g., Welch, 1979), this perspective views teachers as active agents who work together with curriculum materials to develop the planned curriculum and construct the enacted curriculum.

Curriculum materials play an active role in mediating this participatory relationship by enabling and constraining teachers' curricular decision making (Brown, 2009; Remillard, 2005). Shaped by historical, social, and cultural values, curriculum materials contain particular ideas that specify what science concepts are important to teach and what pedagogical methods are most effective. These material resources influence what teachers learn from curriculum materials and how they use them in practice (Cohen \& Ball, 1999). For example, curriculum materials describing innovative pedagogical approaches may promote changes in teachers' knowledge about how to teach the subject matter and ultimately result in changes in their practice.

Teachers also play an active role in the participatory relationship. As teachers read and interpret written materials, they draw upon their experiences, beliefs, knowledge, and instructional goals (Brown, 2009; Remillard, 2005). These personal resources help teachers bring meaning to the materials and ultimately shape how they enact the materials in practice (Cohen \& Ball, 1999). For example, teachers may modify their materials to be responsive to their instructional goals and students' needs. Thus, not only do curriculum materials shape teachers' ideas and practices but teachers also simultaneously shape curriculum materials as they use and adapt the materials in ways that address their own unique characteristics, needs, and goals.

\section{Challenges to Helping Preservice and Beginning Teachers Analyze Curriculum Materials}

A growing body of research has investigated the ways in which teachers use curriculum materials to design and enact instruction (Bullough, 1992; Collopy, 2003; Drake \& Sherin, 2009; Grossman \& Thompson, 2004; Powell, 1997; Remillard, 1999; Schneider \& Krajcik, 2002; Valencia, Place, Martin, \& Grossman, 2006). This research has shown that teachers engage in two important design practices. Teachers critique curriculum materials, that is, identify their strengths and weaknesses (Davis, 2006; Schwarz et al., 2008), and teachers make adaptations to compensate for their deficiencies (Drake \& Sherin, 2006). We use the term analysis to refer to the practices of critique and adaptation simultaneously (Beyer, 2009). 
Teachers' pedagogical design capacity plays a key role in shaping their ability to engage in these design practices. This capacity entails the "ability to perceive and mobilize existing resources in order to craft instructional contexts" (Brown, 2009, p. 24). Developing teachers' pedagogical design capacity is not just a function of developing particular types of knowledge and beliefs. It also includes developing their ability to act upon these personal resources while interacting with particular material resources to design powerful learning opportunities for students (Cohen \& Ball, 1999; Remillard, 2005). Thus, in fostering their pedagogical design capacity, teachers must learn how to negotiate the affordances and constraints of particular curricular features while taking into consideration their own understandings, instructional goals, and classroom needs.

Cultivating the capacity to critique and adapt curriculum materials in productive ways is a challenging task, especially for new teachers. For example, preservice and beginning teachers tend to consider a variety of ideas when they plan with curriculum materials (Davis, 2006; Schwarz et al., 2008), but their ideas are often limited in scope and depth (Bullough, 1992; Lloyd \& Behm, 2005; Mulholland \& Wallace, 2005; Nicol \& Crespo, 2006; Schwarz et al., 2008). Preservice and beginning teachers also tend to struggle with making adaptations, failing to make much needed modifications (Lloyd \& Behm, 2005; Valencia et al., 2006) or making only superficial or counterproductive adaptations to materials (Ball \& Feiman-Nemser, 1988; Grossman \& Thompson, 2004; Nicol \& Crespo, 2006). For these reasons, novice teachers especially need support in developing their pedagogical design capacity for analyzing curriculum materials.

\section{Supporting Preservice Teachers' Analysis of Lesson Plans Using Educative Supports}

This study explores the use of educative curriculum materials in helping preservice teachers engage in productive curricular planning. As noted previously, educative curriculum materials contain curricular supports specifically intended to scaffold teacher learning, in addition to student learning (Ball \& Cohen, 1996; Schneider \& Krajcik, 2002). As teachers interact with curriculum materials in the design of the planned curriculum, these educative supports serve as material resources for teachers by helping them make informed decisions about how to use and adapt their materials. For example, educative supports embedded within curriculum materials may highlight important pedagogical principles for teachers to consider as they make decisions about how to use their materials (Beyer \& Davis, in press). Educative supports may also provide teachers with guidance on how to use and adapt particular curricular suggestions to achieve productive instructional ends (Davis \& Krajcik, 2005; Remillard, 2000; Schneider \& Krajcik, 2002). 
Despite the potential for educative curriculum materials to promote teacher learning, little is known about how educative supports should be written to best support teachers (Beyer \& Davis, in press; Remillard, 2000). Drawing upon Shulman's (1986) categorization of teacher knowledge, this study examines the affordances and constraints in using general versus lesson-specific educative supports. General educative supports are intended to support teachers' propositional knowledge by describing principles of practice that relate to multiple lessons. In contrast, lesson-specific narrative supports aim to support teachers' case knowledge by providing exemplars of principles, describing a lesson-specific instance of the principle in practice. In this study, we aimed to help preservice teachers develop these two types of knowledge (their personal resources). By targeting these two knowledge types, the educative supports aimed to help preservice teachers develop their pedagogical design capacity by expanding their knowledge of principles of practice and helping them successfully apply these principles in their critique and adaptation of lesson plans. Specifically, the educative supports included principles focused on helping the preservice teachers learn how to attend to students' ideas during lessons. Preservice teachers are often not aware of the ways in which students' prior ideas can influence learning and have limited strategies for helping students refine and modify their ideas (Smith, 1999; Smith \& Neale, 1989). Therefore, the educative supports specifically aimed to expand the preservice teachers' knowledge and application of principles related to students' ideas.

To assess the affordances and constraints of the general and lessonspecific supports, we describe how preservice elementary teachers used and learned from the educative supports in their critique and adaptation of science curriculum materials when they received one of the two forms of support. The research questions guiding our study include the following:

1. How do preservice teachers use the different forms of educative supports?

2. What are preservice teachers' views on the usefulness of the different forms of support?

3. How do the different forms of educative supports help preservice teachers ...

a. Apply the principles in their lesson plan analyses?

b. Make specific adaptations related to the principles in their lesson plan analyses?

This study has implications for how teacher educators can support teachers in developing their pedagogical design capacity for analyzing curriculum materials. It also informs the design of educative curriculum materials, shedding light on the ways in which curriculum developers can design supports to best promote teacher learning. 


\section{METHODS}

\section{Research Participants and Context}

This research study focused on two sections of an elementary science methods course at a large Midwestern university in the United States. Of the 56 preservice teachers, 53 gave their consent for us to analyze their coursework for this study. The two different sections were similar with regard to their demographics. The majority of the participants in each section were representative of the population of elementary teachers in the United States-white and female (NCES, 2007). Most of the preservice teachers were also traditional fourth-year college students (21 or 22 years of age) in their final year of study. We use pseudonyms to maintain the confidentiality of the participants.

The two course sections also had similar experiences in the teacher education program. The program consisted of 2 years ( 4 semesters, each 4 months long). It included three semesters of university coursework and field observation and teaching in elementary school classrooms and a final semester of full-time student teaching. Participants from both sections took the same education courses, including foundations of education, educational psychology, and methods courses in literacy, social studies, mathematics, and science. The program was aligned with recommendations outlined by teacher education reform calls and standards documents (e.g., AAAS, 1993; NCSS, 1994; NCTM, 1991; NRC, 1996).

The elementary science methods course met for 3 hours each week during the third semester of the program. The second author taught both sections of the course. Thus, both sections had identical activities and assignments, which were organized around three main themes. The course helped preservice teachers develop their understanding of inquiryoriented science teaching, attend to students' ideas about science in their practice, and critique and adapt science curriculum materials (Davis \& Smithey, 2009). This study specifically focused on the second and third themes of the course.

\section{Lesson Plan Analysis Assignments and Educative Supports}

Preservice teachers completed three lesson plan analysis assignments distributed evenly across the semester. These assignments aimed to develop their pedagogical design capacity for analyzing science curriculum materials. Each assignment contained a different lesson plan, drawn from a unit our group designed and then refined for this study. The unit was provided using the Curriculum Access System for Elementary Science (CASES), an online learning environment that provides new elementary teachers with educative curriculum materials (http://cases.soe.umich.edu/; see Davis, Smithey, \& Petish, 2004). Each assignment asked the preservice teachers to 
identify the lesson's strengths and weaknesses, make adaptations to address the weaknesses, and discuss where their ideas about strengths, weaknesses, and changes came from.

For each assignment, the lesson plan included an educative support intended to help the preservice teachers with their analysis. Each educative support targeted a principle of practice associated with the broad issue of attending to students' ideas. Specifically, the principles focused on identifying, interpreting, and working with students' ideas about science. Principles are economical, decontextualized statements intended to provide pedagogical guidance while simplifying the complexity of teaching (Shulman, 1986).

Both sections of the course received educative supports targeting the same principles as well as the same rationales for attending to those principles. The educative support for the first assignment involved "making thinking visible" (principle 1), which entailed eliciting students' ideas throughout a lesson. For the second assignment, the educative support focused on "probing student thinking" (principle 2), which we defined as uncovering students' explanations for their ideas. The educative support for the third assignment focused on helping students "construct connections between in-class experiences and their science ideas" (principle 3). This principle involved promoting sensemaking by helping students make connections between their initial ideas and the new ideas introduced in class.

These principles served two purposes. First, they were intended to help the preservice teachers identify important ideas that they could use to guide their analyses. Second, phrases associated with each principle (e.g., "making thinking visible," "probing student thinking") served as "tracers" to help us determine if and when the preservice teachers used the educative supports in their analyses. When the preservice teachers mentioned the specific phrases, we were able to determine which of their claims about the strengths and weaknesses of the lesson plan came from their use of the educative supports, enabling us to make assertions about where the preservice teachers obtained some of their analysis ideas.

\section{Study Design}

We used a quasi-experimental approach in the design of the study. We had two treatment conditions, each corresponding to a section of the science methods course. Both sections received educative supports as part of their lesson plan analysis assignments, but the supports differed with regard to their degree of generality. One section with 28 participants received general educative supports. These supports explicitly highlighted a general principle of practice by describing its meaning and importance apart from a specific situation, context, or lesson plan. For example, one support 
targeted the principle "probe student thinking" by detailing what it means to probe beneath students' ideas and providing several reasons for why teachers should attend to this principle in their curricular analysis. We designed the supports in this way to help the preservice teachers learn about some key pedagogical ideas and recognize these ideas as applicable to multiple contexts and lesson plans.

The other course section with 25 participants received lesson-specific supports. These supports implicitly highlighted a general principle of practice by describing an exemplar of the principle in the form of a story. These narratives depicted a specific instructional event related to the principle and the lesson plan that accompanied the principle. For example, one support described how a fictional teacher named Kendra used the principle "probing student thinking" to identify a specific modification that she could make to the lesson plan to probe deeper into students' initial ideas about the science content. We designed the supports in this way to help the preservice teachers understand how a particular principle might be applied within a specific lesson plan and to help them remember the principle by grounding it within a particular context.

See Figures 1 and 2 for examples of the general and lesson-specific supports that the preservice teachers received in the lesson plan analysis assignments.

In this study, we wanted to test our hypotheses about the specific effects of each form of support, given the paucity of research on this topic.

Overarching Principle: Teachers need to identify, interpret, work with, and support students' ideas to help students make sense of the science.

General Principle: Teachers need to probe student thinking.

Students have a range of ideas about scientific phenomena. Some of students' ideas are based on their experiences in the natural world and their perceptions of those experiences. Others develop from things their parents, teachers, or peers have told them in the past. These ideas influence how students learn new ideas. Therefore, it is important to probe student thinking. This means to find ways to uncover and interpret students' ideas by providing opportunities for students not only to state WHAT ideas they have, but also WHY they have particular ideas.

Why is this important? Probing student thinking helps teachers assess student understanding. Students may provide the teacher with answers they want to hear or may sound like they understand but really don't. Therefore, unpacking students' ideas helps teachers determine if students really understand a concept or not. Probing student thinking also helps teachers recognize what is reasonable about students' ideas. Sometimes ideas sound off-the-wall, but once a teacher digs deeper, the teacher can see where the idea came from and see that it makes a lot of sense in certain situations. Knowing where or how students have developed particular ideas can help teachers have a better idea about how to work with them to help students move toward a more accurate understanding of the science.

FIGURE 1. Example of general educative support. 
When Kendra taught this lesson, she wanted to make sure she probed her students' thinking to understand it. She began the lesson by showing the before/after puddle pictures and asking the students, "What happened to the water in the puddle?" Some students said that the water had soaked into the soil, while other students said they thought the water had disappeared. To get a better idea of why they held these ideas, Kendra decided to further probe student thinking. She followed up her initial question with questions like, "What do you mean by that? Can you tell me more about that? Why do you think that is the case?" Kendra found out that the students who thought the water soaked into the ground had seen water soak into soil. She also found out that some other students really thought that the water was gone forever, not that the water had simply gone into the air. And for good reason, because all of their experiences pointed to the water "disappearing." Kendra was glad that she continued to probe students' thinking. She realized that sometimes her students sound like they understand when they really do not. She also realized how reasonable her students' ideas were even though they might not be scientifically accurate. Finally, by probing student thinking, Kendra was able to find out why her students held particular ideas. This information helped her know what instructional strategies she might use to help her students examine and refine their thinking during the investigation.

FIGURE 2. Example of lesson-specific, narrative educative support.

Specifically, we hypothesized that the preservice teachers who received the general supports would be more likely to see the targeted principle as a criterion in which to analyze the entire lesson plan but would not necessarily successfully identify and address a particular weakness within the lesson plan dealing with the principle. In contrast, we hypothesized that the preservice teachers who received the lesson-specific supports would be more likely to identify a specific way to improve the lesson plan with regard to the targeted principle but would not necessary apply the principle to other parts of the lesson plan in their analysis. Additionally, we hypothesized that the preservice teachers who received the general supports would see the targeted principle as applicable to other lesson plans in addition to the one that they were asked to analyze using the support whereas the preservice teachers who received the lesson-specific supports would not be able to extract the principle from its specific context and apply to other contexts. However, we hypothesized that the preservice teachers might see the lesson-specific narratives as more relevant and useful than the general, expository supports because the supports were clearly related to the lesson plan that they were asked to analyze and were more personal by providing insights into the thoughts of another teacher. Of course, if these hypotheses about the specific effects of each form of support prove to be roughly correct, then it stands to reason that a combination of the supports may be most effective in scaffolding the preservice teachers' lesson plan analyses. 


\section{Data Sources}

As previously described, both sections of the course completed three lesson plan analysis assignments. These assignments shed light on how the preservice teachers used two different forms of educative supports and what they learned from them. The preservice teachers also completed identical pre-/posttests as homework at the beginning and end of the semester. Like the lesson plan analysis assignments, the pre-/posttests asked preservice teachers to identify strengths and weaknesses, make adaptations, and discuss the origin of their analysis ideas. However, the pre-/posttests did not include any educative supports. We used the pre-/posttests to describe whether the preservice teachers used the principles and tracers in their analyses when they did not receive the supports.

We also conducted interviews with a subset of the preservice teachers-three from the lesson-specific group and four from the general group. These interviews took place at the beginning, middle, and end of the course. All three interviews lasted approximately 1 hour and were audio recorded and transcribed. In the first and third interviews, the preservice teachers discussed their ideas about what it means to identify, interpret, and work with students' ideas about science and why these practices are important in science teaching. They then described their pre-/posttest analyses and the origin of their analysis ideas. In the second interview, the preservice teachers described how they completed the lesson plan analysis assignments and used the educative supports in their analyses. They also discussed their perceptions on the usefulness of the educative supports. As part of a think-aloud (Ericsson \& Simon, 1993), the preservice teachers shared any thoughts they had as they read through one of the lesson plans and educative supports from their lesson plan analysis assignments.

\section{Data Coding and Analysis}

Data analysis consisted of iterative analysis and revision of the coding scheme (Miles \& Huberman, 1994). We used ideas embedded in the educative supports to construct the initial coding scheme. During analysis, we identified emergent codes, added them to the coding key, and recoded all of the data using a finalized coding scheme, which included the following five categories: (1) preservice teachers' use of the educative supports, (2) views on the usefulness of the supports, (3) use of the instructional strategies described in the narratives, (4) origin of their analysis ideas, and (5) use of tracers from the educative supports. Table 1 includes the categories and codes used in the analysis. We then quantified some of the codes to help us make meaningful comparisons between 
TABLE 1

Coding Scheme for All Data Sources

\begin{tabular}{|c|c|c|}
\hline Code & Subcode & Description \\
\hline \multirow[t]{3}{*}{ Principles } & Make thinking visible & $\begin{array}{l}\text { Enable students to communicate their ideas } \\
\text { to teachers and peers }\end{array}$ \\
\hline & Probe student thinking & $\begin{array}{l}\text { Enable students to explain WHY they have } \\
\text { particular ideas }\end{array}$ \\
\hline & Construct connections & $\begin{array}{l}\text { Enable students to examine their initial } \\
\text { ideas in light of what they learn from } \\
\text { in-class experiences }\end{array}$ \\
\hline \multirow[t]{4}{*}{ Tracers } & Assignment 1 tracers & Make thinking visible; MTV \\
\hline & Assignment 2 tracers & Probe students' thinking \\
\hline & Assignment 3 tracers & Construct connections \\
\hline & Other tracers & $\begin{array}{l}\text { Story, Kendra, principle, pink sheet, yellow } \\
\text { sheet* }\end{array}$ \\
\hline \multirow{6}{*}{$\begin{array}{l}\text { Use of } \\
\text { Educative } \\
\text { Supports }\end{array}$} & Read supports & Read the educative supports \\
\hline & Not read supports & Do not read the educative supports \\
\hline & Discuss rationales & Discuss rationales mentioned in support \\
\hline & Discuss strategies & Discuss the instructional strategy in support \\
\hline & Relate principles & $\begin{array}{l}\text { Relate principle to experiences as learners } \\
\text { and teachers }\end{array}$ \\
\hline & Apply principles & $\begin{array}{l}\text { Find strengths/weaknesses in the lesson } \\
\text { related to principle and make relevant } \\
\text { modifications }\end{array}$ \\
\hline \multirow{4}{*}{$\begin{array}{l}\text { Views on Usefulness } \\
\text { of Educative } \\
\text { Supports }\end{array}$} & Visualize lesson & $\begin{array}{l}\text { Illustrate what lesson would look like in } \\
\text { practice }\end{array}$ \\
\hline & Address problem & Address a specific issue with the lesson \\
\hline & Modify lesson & $\begin{array}{l}\text { Recognize that it is okay to modify lesson } \\
\text { plans }\end{array}$ \\
\hline & Identify criteria & Identify criteria for analyzing lesson plans \\
\hline \multirow[t]{5}{*}{$\begin{array}{l}\text { Instructional } \\
\text { Approaches }\end{array}$} & Whole-class discussion & $\begin{array}{l}\text { Have students share their ideas with the } \\
\text { whole class at start of lesson (from } \\
\text { principle 1) }\end{array}$ \\
\hline & Record ideas publicly & $\begin{array}{l}\text { Record students' ideas/observations/ } \\
\text { findings for the whole class to see (from } \\
\text { principle 1) }\end{array}$ \\
\hline & Ask probing questions & $\begin{array}{l}\text { Ask follow-up questions that probe students' } \\
\text { surface ideas (from principle } 2 \text { ) }\end{array}$ \\
\hline & Use worksheet & $\begin{array}{l}\text { Use a chart that helps students compare } \\
\text { models with the real world (from } \\
\text { principle } 3 \text { ) }\end{array}$ \\
\hline & $\begin{array}{l}\text { Revisit students' } \\
\quad \text { initial ideas }\end{array}$ & $\begin{array}{l}\text { Revisit question posed at start of lesson } \\
\text { to see how students' ideas have changed } \\
\text { (from principle } 3 \text { ) }\end{array}$ \\
\hline \multirow[t]{9}{*}{ Origin of Ideas } & Science methods & Class discussions, readings, etc. \\
\hline & Education classes & $\begin{array}{l}\text { Other education classes besides science } \\
\text { methods }\end{array}$ \\
\hline & Science learning & Experiences as science learners \\
\hline & Student learning & Experiences as a student, in general \\
\hline & Educative supports & Educative supports in analysis assignments \\
\hline & Teaching experience & Their own experiences teaching lessons \\
\hline & Teacher sense & Visualizing the lesson as a teacher \\
\hline & Student sense & $\begin{array}{l}\text { Predicting how students will experience } \\
\text { lesson }\end{array}$ \\
\hline & Cooperating teacher & $\begin{array}{l}\text { Talking with or observing cooperating } \\
\text { teacher }\end{array}$ \\
\hline
\end{tabular}

* The general group received their educative supports on yellow sheets of paper while the lesson-specific group received their educative supports on pink sheets. 
treatment conditions (Chi, 1997). Within the lesson plan analysis assignments, we calculated the percentage of preservice teachers from each section of the course who attended to each principle and used tracers in each assignment, attributed their analysis ideas to the educative supports, and attended to instructional approaches described in the narratives.

Next we identified themes in the coded and quantified data dealing with similarities and differences between the two treatment conditions with regard to their use of the educative supports, perceptions of their usefulness, and application of the principles and instructional approaches in their analyses. We then developed preliminary assertions for each research question based on the themes that we had identified and uncovered confirming and disconfirming evidence to test the viability of these assertions (Erickson, 1986). We enhanced the validity of the study by triangulating data among the interviews, pre-/posttests, and lesson plan analysis assignments to support the most robust assertions. Finally, we sought feedback from colleagues on the coding schemes and emergent patterns, further contributing to the credibility of the assertions in this study (Lincoln \& Guba, 1985).

\section{RESULTS}

This section describes preservice elementary teachers' views on and uses of the educative supports and the impact of these supports on their analysis of science lesson plans. We first show the degree to which the preservice teachers in each class section used the educative supports when they completed the lesson plan analysis assignments. Next we describe each treatment condition's views on the usefulness of the educative supports that they had received. We conclude by examining the extent to which the preservice teachers applied the principles in their lesson plan analyses and made specific adaptations related to the principles.

\section{Use of the Educative Supports}

Most of the preservice teachers in the lesson-specific group but only some of the preservice teachers in the general group used the educative supports in their lesson plan analysis assignments. For example, all of the interviewees from the lesson-specific group and two of the four interviewees from the general group said that they used the supports to inform their analysis when completing the assignments. Summer shared:

I read [the lesson plan] through first, and as I read, I make notations if something stands out to me. Then I read this [educative support] because [the instructor] 
always gives us one of these for each of them-a principle to focus on as we're doing this. So then I read this and I think about the lesson again in terms of this principle. (Summer, General Group, Interview 2)

In contrast, two interviewees from the general group stated that they completed the lesson plan analysis assignments by only reading the lesson plan. Sally described how she completed the assignments without the use of the educative supports:

First I read one time and then I read through a second time and then I make comments in the margin about my initial reactions to some of the things and then I go to the questions, like describe the strengths, weaknesses, and changes. And I look at my comments in the margins and basically match it up to the category. (Sally, General Group, Interview 2)

The percentage of preservice teachers mentioning the tracers from the educative supports in their analysis provides additional evidence that more preservice teachers in the lesson-specific group than in the general group used the educative supports. The educative supports from the first, second, and third lesson plan analysis assignments included the tracers "making thinking visible," "probing student thinking," and "constructing connections," respectively. Other tracers specific to the narratives included "Kendra" (the name of the fictional teacher), "story," and "pink sheet," while other tracers specific to the general supports included "principle" and "yellow sheet." Roughly three-fourths of the lesson-specific group, on average, mentioned a tracer in each assignment, whereas only half of the general group used the tracers (see Table 2). This finding shows that most of the preservice teachers in the lesson-specific group actually read and used the educative supports, in contrast to the general group.

When the preservice teachers used the educative supports in their lesson plan analyses, they discussed different ideas depending on the form of support they received. The lesson-specific group tended to have one main response. They tended to mention that they liked the adaptation that the

TABLE 2

Percentage of Preservice Teachers Who Used Tracers in Their Lesson Plan Analysis Assignments

\begin{tabular}{lcc}
\hline \hline Assignment & \multicolumn{2}{c}{$\begin{array}{c}\text { Percentage of Preservice } \\
\text { Teachers Who Mentioned Tracers }\end{array}$} \\
\cline { 2 - 3 } & Lesson-Specific Group & General Group \\
\hline Lesson Plan Analysis Assignment 1 & $84 \%$ & $45 \%$ \\
Lesson Plan Analysis Assignment 2 & $72 \%$ & $47 \%$ \\
Lesson Plan Analysis Assignment 3 & $76 \%$ & $57 \%$ \\
Average Across Assignments & $77 \%$ & $50 \%$ \\
\hline
\end{tabular}


fictional teacher made. Eva expressed this idea after using the support focused on helping students construct connections between in-class activities and their ideas:

I agree with [Kendra] . . . I like that idea [of revisiting the initial question at the end of the lesson] just because it gives them a chance to reflect and think about, "Okay, so this is what I thought at the beginning of this. And how have my ideas changed and what am I still confused about?" (Eva, Lesson-Specific Group, Interview 2)

Eva's response gives an example of how the lesson-specific group tended to focus on the lesson-specific features of the supports but not on the principle underlying those features.

In contrast, when the preservice teachers used the general supports in their analyses, they gave several different responses focused on the principle targeted in the educative support. The preservice teachers provided rationales for the principle's importance, related it to their personal experiences as learners and teachers, and related it to the lesson plan itself. For example, Kayla shared some of these ideas when discussing the "constructing connections" principle. She said:

This is a really important lens because I think if we aren't helping kids to make these connections they kind of (a) don't understand why they're doing certain things and (b) it's not meaningful to them. I mean that's a big reason why I didn't like science when I was little because I didn't really know why we were doing something. (Kayla, General Group, Interview 2)

In addition to these ideas, some preservice teachers from the general group also made suggestions for how to adapt the lesson plan to better address the principle and provided rationales for their adaptations. For example, Lily described how she would add a whole-class discussion at the end of the lesson to help students construct connections between the cloud model and the real phenomenon.

It's probably a good idea to just bring all of it out in the open ... because they might not see these [connections] on their own but with support they can do so. I feel like it's hard to connect this model and the real world. But if you have a discussion about it and you make that explicit to them, it's more likely that they'll be able to keep that connection in their head, and not just think about the experiment with the eraser and salt. (Lily, General Group, Interview 2)

These typical examples show that the general group tended to focus on the principle targeted in the supports and connect it with prior experiences as well as to the specific lesson plan accompanying the educative support.

In sum, most of the preservice teachers in the lesson-specific group used the educative supports but only some of the preservice teachers in the general group did so. When the preservice teachers did use the educative 
supports, the supports elicited different types of ideas between the two treatment conditions. The lesson-specific group focused almost exclusively on the lesson-specific features of the educative support, whereas the general group was able to identify the principle targeted in the supports and apply it to the specific lesson plan that they were given.

\section{Perceptions of the Usefulness of the Educative Supports}

The preservice teachers' perceptions of the usefulness of the educative supports differed greatly between the two treatment conditions. The lessonspecific group gave several different reasons why they viewed their narrative supports as useful. First, they saw the supports as helping them visualize what the lesson would look like in practice. Tracy explained, "[The support] helps me see just how it would be carried out, because this [lesson plan] is all very theoretical, and this [support] is more like how it would go in a classroom" (Interview 2). The lesson-specific group also viewed the educative support as useful for seeing how the lesson plan could be modified to address a particular need. For example, Eva explained how she used the support to help her address a specific issue with the lesson, saying, "It gave me a clear example and [Kendra's] reasoning behind it of why you might change something and how you would change it" (Interview 2). The preservice teachers also viewed the narrative supports as useful for helping them recognize that it is a part of a teacher's job to modify lesson plans. For example, Holly explained that the supports helped her see that it is acceptable to make changes to lesson plans. She said, "It reinforces the idea of being reflective and to not always take everything for face value. Because each time it's mainly the teacher who's put thought into the lesson and then changed it in some way" (Interview 2). These typical examples show that the lesson-specific group expressed a variety of reasons for why they viewed their supports as useful.

In contrast to the lesson-specific group, the preservice teachers interviewed in the general group gave only one main reason for using the educative supports, that is, to help them identify ideas to guide their analysis of lesson plans. Summer shared this reason, saying, "I think it's another lens with which to look at lessons, so in that way I find it useful. It just raises your awareness of another aspect of the lesson to analyze" (Interview 2). Similarly, in discussing where they got their ideas about how to analyze lesson plans, the interviewees frequently mentioned that the general supports provided them with their ideas (see Table 3). Interestingly, this was not true of the lesson-specific group, even though more preservice teachers in this group tended to use the educative supports, in comparison to the general group. In discussing the origin of her analysis ideas, Summer explained that some of her ideas came from the general educative support, writing, "My idea for this possible change to the lesson 
TABLE 3

Percentage of Preservice Teachers Attributing Their Analysis Ideas to Educative Supports

\begin{tabular}{lcc}
\hline \hline Assignment & \multicolumn{2}{c}{$\begin{array}{c}\text { Percentage of Preservice Teachers } \\
\text { Attributing Analysis Ideas to } \\
\text { Educative Supports }\end{array}$} \\
\cline { 2 - 3 } & \multicolumn{2}{c}{$\begin{array}{c}\text { Lesson-Specific Group } \\
\text { General Group }\end{array}$} \\
\hline Lesson Plan Analysis Assignment 1 & $12 \%$ & $45 \%$ \\
Lesson Plan Analysis Assignment 2 & $4 \%$ & $47 \%$ \\
Lesson Plan Analysis Assignment 3 & $0 \%$ & $47 \%$ \\
Posttest & $0 \%$ & $25 \%$ \\
\hline
\end{tabular}

came from the principle given on the Lesson Plan Analysis assignment sheet. This principle helped me see the importance of probing student thinking" (Assignment 2). Chloe added, "At the end of the term I plan on compiling these principles and keeping them as a resource I can use later to think about and modify lessons" (Assignment 3).

In sum, the lesson-specific group gave a variety of reasons for the usefulness of their educative supports, in contrast to the general group who only saw their supports as useful for one main reason. However, unlike the lesson-specific group, the general group's views on the usefulness of the supports extended to the principles themselves. They recognized the principles in the educative supports as useful for helping them analyze science lesson plans.

\section{Use of the Principles in the Analysis of Lesson Plans}

When the preservice teachers completed the lesson plan analysis assignments, both conditions attended to the principle referenced in the educative supports when they received the educative support that corresponded to that principle (see Table 4). This trend was consistent for all three principles. (However, consistently fewer preservice teachers in the general group discussed ideas related to the principle, possibly because fewer preservice teachers in this group used the educative supports, in comparison to the lesson-specific group, as described above.)

Even though both treatment conditions attended to the principles in their analyses, they attended to them in different ways. The lesson-specific group tended to focus solely on the specific instance of the principle described in the educative supports. For example, Kraig attended to the principle "probing student thinking" by focusing exclusively on the way the fictional teacher applied the principle in the lesson plan, writing, "I liked how Kendra further probed the students' thinking to have a very clear 
TABLE 4

Percentage of Preservice Teachers Who Attended to the Targeted Principle in Their Analysis

\begin{tabular}{lcc}
\hline \hline Assignment & \multicolumn{2}{c}{$\begin{array}{c}\text { Percentage of Preservice } \\
\text { Teachers Attending to Principle }\end{array}$} \\
\cline { 2 - 3 } & Lesson-Specific Group & General Group \\
\hline Lesson Plan Analysis Assignment 1 & $100 \%$ & $68 \%$ \\
Lesson Plan Analysis Assignment 2 & $72 \%$ & $50 \%$ \\
Lesson Plan Analysis Assignment 3 & $96 \%$ & $72 \%$ \\
\hline
\end{tabular}

understanding of what the students' alternative ideas were, so that she could focus and guide the lesson in a way that would best address these misconceptions" (Assignment 2). This typical example shows how the lesson-specific group tended to focus on the specific ideas in the narrative support but not on the principles underlying those ideas.

In contrast, the general group attended to the principles in the educative support by identifying multiple strengths and/or weaknesses and making modifications to improve the lesson with regard to the principles. Sophie's use of the principle "probing student thinking" demonstrates this approach:

The lesson does not provide a lot of opportunity for the teacher to probe student thinking plus follow up on student ideas. When the lesson begins and when Day 1 begins, there are several questions listed that the teacher can ask to see what initial ideas students have. The teacher is then expected to move on to the rest of the lesson, though, without addressing how or why students had these ideas. Part 8 on Day 2 is similar, asking students to discuss questions as a class, but never asking students to explain where their ideas came from.... A great way to improve in this way is that a few possible questions could be added during discussion times. The teacher could ask in part 1 of Day 1, "Why do you think that?" after students share their prior ideas... (Sophie, General Group, Assignment 2)

Sophie identified two weaknesses with regard to the principle and made adaptations to address these deficiencies. Thus, like others in the general group, she engaged in a thorough analysis of the lesson plan with regard to the principle from the supports.

The interview data provides further evidence that the general group used the principles as criteria for analyzing lesson plans. The following excerpt illustrates this use:

I focus on the principle for the class period, when I go back through [the lesson] ... I like that we have a different principle every time we do a plan because I think that otherwise, you tend to pinpoint the exact same things over and over again. ... I just think it's important to step away from your own thoughts and use these when looking at it. (Kayla, General Group, Interview 2) 
Kayla's comments provide a typical example of how, in contrast to the lesson-specific group, the general group tended to use the principle to guide their analysis of the entire lesson plan, engaging in a more systematic analysis with regard to the principle.

Additionally, a few individuals in the general group continued to apply the principles in subsequent analyses. For example, Kayla used the principles from previous assignments in her posttest analysis and explained why she did so, saying, "When we get these [educative supports], we have a specific lens to look at, and we didn't have anything [on the posttest], so I feel like I automatically started thinking about the lenses we used previously in the semester" (Interview 3). In addition to Kayla, $25 \%$ of the preservice teachers in the general group applied the principles in the posttest, and in contrast to the lesson-specific group, attributed their analysis ideas to the educative supports (see Table 3). For example, Nadia used all three principles from previous educative supports to assess the strengths and weaknesses of the lesson plan (and she also mentioned relevant tracers). She wrote:

- [The lesson] opens the door for students to construct connections between in-class experiences and ideas about science concepts. By having them view and understand the process of condensation in their cups, they could link what they've learned to the process of condensation in clouds or dew-covered grass (however, the teacher may need to help them draw such connections, which the lesson doesn't mention.) ...

- It makes the students' thinking visible ("MTV") by having them share their own views for how and why condensation occurs on the surface of the cup. This refers to both the initial question regarding the lemonade glass on a summer day and the students' beliefs regarding what had happened during the experiment.

- It allows the teacher to probe student thinking by asking questions like "What happens to the lemonade glass during a hot day outside?" or "What do you think the stuff on the cup's surface is?" or finally "Where do you think it came from and how can you test your guess?" This way, the teacher could learn about what the students do and don't know about condensation... (Nadia, General Group, Posttest, italics added to denote tracers)

In sum, the majority of the preservice teachers from both treatment groups attended to the principle when they received the educative supports corresponding to that principle, but the two groups attended to the principles in different ways. The lesson-specific group focused on the lesson-specific ideas in the narrative educative support but not on the principle underlying those ideas, resulting in missed opportunities to further improve the lesson with regard to the principle. In contrast, the general group used the principle to identify multiple strengths and/or weaknesses in the lesson plan. In addition, some individuals from the general group continued to use the principles as criteria in their critique and adaptation of other lesson plans. These individuals also used the 
tracers and asserted that their analysis ideas came from the educative supports, suggesting that the supports themselves enhanced their pedagogical design capacity by helping them identify important principles for analyzing curriculum materials.

\section{Application of Specific Adaptations in the Analysis of Lesson Plans}

The lesson-specific narrative supports described how a fictional teacher made adaptations to improve the lesson plan with regard to the principle targeted in the educative support. Thus, unlike the general supports, the lesson-specific supports described particular instructional approaches that the preservice teachers could use to modify the lesson. Results show that the two treatment conditions differed in the extent to which they applied these specific adaptations in their lesson plan analyses. Consistently more preservice teachers in the lesson-specific group mentioned the specific instructional strategy in their analysis when they received the corresponding educative support than those in the general group (see Table 5). In fact, for the primary adaptation discussed in each narrative, two-thirds or more of the lesson-specific group mentioned the adaptation in their analysis whereas only a quarter or less of the general group made the same modification.

The narrative support in the first lesson plan analysis assignment targeted the principle of "making thinking visible" and described how the fictional teacher Kendra modified the lesson to have a whole-class discussion at the beginning of the lesson and record students' ideas on chart

TABLE 5

Percentage of Preservice Teachers Who Applied Specific Instructional Approaches in the Lesson Plan Analysis Assignments

\begin{tabular}{lccc}
\hline \hline Assignment & $\begin{array}{c}\text { Instructional Approach } \\
\text { Described in } \\
\text { Lesson-Specific Support }\end{array}$ & $\begin{array}{c}\text { Percentage of Preservice } \\
\text { Teachers Who Applied } \\
\text { Instructional Approach }\end{array}$ \\
\cline { 3 - 4 } & & $\begin{array}{c}\text { Lesson-Specific } \\
\text { Group }\end{array}$ & $\begin{array}{c}\text { General } \\
\text { Group }\end{array}$ \\
\hline Lesson Plan Analysis 1 & $\begin{array}{c}\text { Whole-class discussion at } \\
\text { beginning of lesson* } \\
\text { Record ideas publicly at } \\
\text { beginning of lesson }\end{array}$ & $88 \%$ & $24 \%$ \\
Lesson Plan Analysis 2 & $\begin{array}{c}\text { Ask probing questions* } \\
\text { Lesson Plan Analysis 3 } \\
\text { Revisit students' ideas }\end{array}$ & $72 \%$ & $11 \%$ \\
& Revison work & $68 \%$ & $29 \%$ \\
\hline
\end{tabular}

* Denotes the primary instructional strategy emphasized in the lesson-specific supports. 
paper. Cassie mentioned that she liked both of the strategies that Kendra used to improve the lesson with regard to this principle. She wrote:

I liked how Kendra, the teacher, changed the lesson and brought the whole class together after sharing in smaller groups in order to discuss their thoughts and 'make them visible' by recording in a chart. This allows the students to get a sense for other groups' ideas and to get the class thinking along the same page before jumping into the lesson. (Cassie, Lesson-Specific Group, Assignment 1)

In the narrative associated with the second lesson plan analysis assignment, the fictional teacher modified the lesson to include guiding questions to "probe student thinking"- the principle underlying the educative support. Wendy discussed this instructional strategy in her analysis, writing:

One strength that I saw in Kendra's lesson modification was her intentions of wanting to probe students' thinking to understand the lesson. In probing the students to further explain their reasoning, she was able to identify that students had different interpretations and definition for the words 'disappearing' and 'evaporating.' (Wendy, Lesson-Specific Group, Assignment 2)

The narrative in the final assignment emphasized "constructing connections"-the third pedagogical principle-by describing how the fictional teacher incorporated a worksheet to help students compare a model of a cloud with the real-world phenomena. Patricia incorporated this instructional strategy as she modified the lesson plan:

Kendra's suggestions are needed for the original lesson plan to be effective. Providing an accompanying worksheet to have students draw and label both situations is helpful so they can make a visual comparison between model and actuality. This way, students are also forced to understand what goes where, as they have to consider the items they have when labeling their pictures. They may start to make connections between the two pictures at this point. (Patricia, Lesson-Specific Group, Assignment 3)

These typical examples show that the preservice teachers from the lessonspecific group incorporated the specific adaptations described in the narrative educative supports.

In sum, the lesson-specific supports helped the preservice teachers consider specific adaptations and use them in their analysis when they used the educative supports.

\section{DISCUSSION AND IMPLICATIONS}

The way in which educative supports are written may influence how teachers use them and what they learn from them (Beyer \& Davis, in press; Dietz \& Davis, 2009; Remillard, 2000). This study investigated the affordances 
and constraints of different forms of educative supports in supporting preservice elementary teachers' analysis of lesson plans. The preservice teachers receiving the lesson-specific narrative supports tended to focus primarily on the ideas in the supports related to the specific lesson plan that was discussed. This focus led them to incorporate specific instructional strategies in adapting the lesson plans. It also helped them view the supports as useful in many ways; this finding is similar to another study we conducted with the narratives (Dietz \& Davis, 2009). These views motivated them to use the lesson-specific supports in their lesson plan analyses. However, the lesson-specific nature of the supports made it difficult for the preservice teachers to recognize the principle underlying the ideas in the supports. Thus, most of them did not use the principle within the educative supports to analyze the lesson plan more broadly or analyze other lesson plans, resulting in missed opportunities to further improve the materials beyond the suggestions given in the support.

In contrast, the preservice teachers receiving general supports tended to focus on the principle in the support. As a result, the preservice teachers viewed the support as useful for analyzing lesson plans, leading them to apply the principle as a criterion in their lesson plan analysis assignments. This meant that the preservice teachers applied the principle more broadly in their analysis, which included identifying a wide range of adaptations that they could make. A few preservice teachers also continued to use the principles to guide their critique and adaptation of other lesson plans. These findings suggest that the general supports promoted the development of some preservice teachers' pedagogical design capacity by helping them identify important principles for analyzing curriculum materials. However, because the general supports were not embedded within the activities of a specific lesson plan, they did not help the preservice teachers identify specific ways in which they could apply the principles in their analysis. In addition, the preservice teachers expressed limited views on the usefulness of the supports, with some not even viewing the supports as useful at all. As a result, some individuals chose not to read the supports, much less use them in their analyses.

These results have implications for the design of educative curriculum materials. In developing educative supports, a blend of both lesson-specific and general features may best promote teachers' pedagogical design capacity. To help teachers see how the ideas in an educative support are relevant to a specific lesson, curriculum developers need to embed the supports within the context of a lesson, as the lesson-specific supports were designed in this study. Contextualizing support for teachers may help them see the educative support as useful and thus motivate them to actually read and use it in their practice. Additionally, lesson-specific supports that explain why and how to use particular instructional strategies may help teachers make informed decisions about whether and how to use the strategies with their own students (Beyer \& Davis, in press; Remillard, 2000; Schneider \& 
Krajcik, 2002). On the other hand, to help teachers see that the lessonspecific ideas in an educative support are grounded within a more abstract pedagogical principle, curriculum developers need to make the principle underlying those ideas explicit to the teacher, like how the general supports were designed in this study. This may help teachers identify and consider important pedagogical principles in planning for instruction as well as recognize how the ideas in the educative supports may be relevant to other lesson plans.

These results also have implications for teacher education and professional development. To help teachers identify important criteria for analyzing lesson plans, teacher educators need to help them learn about pedagogical principles that represent important ideas about teaching and learning. This may help teachers expand and refine their ideas about effective teaching (Davis, 2006; Schwarz et al., 2008). Additionally, these pedagogical principles need to be explicitly linked to lesson plan analysis tasks to help teachers recognize that they can use these principles as they engage in curricular planning (Beyer, 2009). On the other hand, to help teachers contextualize these pedagogical principles within specific lessons, teacher educators need to allow teachers to examine curricular examples related to the principles. This may help them think thoughtfully about specific aspects of lessons and thus develop their pedagogical design capacity for critiquing and adapting curriculum materials.

This study also provides theoretical insights into the teacher-curriculum participatory relationship. Within this partnership, both the teacher and the curriculum materials participate jointly in the design of the planned and enacted curriculum (Brown, 2009; Remillard, 2005). The findings from this study, dealing specifically with preservice elementary teachers and science curriculum materials, shed light on an important factor to consider when examining this relationship. Our findings suggest that the use of tools plays an important role in scaffolding preservice teachers' (and possibly other teachers') interaction with curriculum materials. In particular, the use of educative supports as tools may help preservice teachers learn about different principles of practice and consider these principles in developing curricular plans.

This study informs several research questions regarding how to help preservice teachers engage in productive curricular planning. However, its contributions must be recognized within the specific context of this study and other questions still remain. While the results from this study suggest that preservice teachers may benefit from educative supports that include both lesson-specific and general features, additional studies are needed to determine what can be learned from such supports. In particular, how do preservice teachers use educative supports that include both lesson-specific and general features when they analyze lesson plans, and what do they learn from them? How do their knowledge and beliefs about teaching and learning mediate their interactions with the educative supports? Other 
studies are also needed to investigate other features of educative supports and how they may support preservice teachers in learning how to critique and adapt lesson plans. Finally, while this study did not examine practicing teachers' interactions with educative supports, the field could capitalize on studies examining how inservice teachers use and learn from different types of educative supports embedded within curriculum materials. Addressing these questions and others will further illuminate how educative supports can support preservice and inservice teachers as they engage in curricular design making.

\section{ACKNOWLEDGMENTS}

This research is funded by a PECASE/CAREER Award, grant number REC-0092610, and by the Center for Curriculum Materials in Science, CLT grant number 0227557, both from the National Science Foundation. Any opinions, findings, conclusions, or recommendations expressed in this material are those of the authors. The authors thank the CASES research team for their feedback and the preservice teachers for their interest and participation.

\section{REFERENCES}

American Association for the Advancement of Science (AAAS). (1993). Benchmarks for science literacy. New York: Oxford University Press.

Ball, D. L., \& Cohen, D. K. (1996). Reform by the book: What is-or might be-the role of curriculum materials in teacher learning and instructional reform? $E d u-$ cational Researcher, 25(9), 6-8, 14.

Ball, D. L., \& Feiman-Nemser, S. (1988). Using textbooks and teachers' guides: A dilemma for beginning teachers and teacher educators. Curriculum Inquiry, $18(4), 401-423$.

Beyer, C. J. (2009). Using reform-based criteria to support the development of preservice elementary teachers' pedagogical design capacity for analyzing science curriculum materials. Unpublished doctoral dissertation, University of Michigan, Ann Arbor.

Beyer, C. J., \& Davis, E. A. (in press). Supporting preservice elementary teachers' critique and adaptation of science curriculum materials using educative curriculum materials. Journal of Science Teacher Education.

Brown, M. W. (2009). The teacher-tool relationship: Theorizing the design and use of curriculum materials. In J. T. Remillard, B. A. Herbel-Eisenmann, \& G. M. Lloyd (Eds.), Mathematics teachers at work: Connecting curriculum materials and classroom instruction (pp. 17-36). New York: Routledge.

Bullough, R. V. J. (1992). Beginning teacher curriculum decision making, personal teaching metaphors, and teacher education. Teaching $\mathcal{E}$ Teacher Education, 8(3), 239-252.

Chi, M. (1997). Quantifying qualitative analyses of verbal data: A practical guide. The Journal of the Learning Sciences, 6(3), 271-315.

Cohen, D. K., \& Ball, D. L. (1999). Instruction, capacity, and improvement. Philadelphia: Consortium for Policy Research in Education, University of Pennsylvania (CPRE RR-43). 
Collopy, R. (2003). Curriculum materials as a professional development tool: How a mathematics textbook affected two teachers' learning. The Elementary School Journal, 103(3), 227-311.

Davis, E. A. (2006). Preservice elementary teachers' critique of instructional materials for science. Science Education, 90(2), 348-375.

Davis, E. A., \& Krajcik, J. (2005). Designing educative curriculum materials to promote teacher learning. Educational Researcher, 34(3), 3-14.

Davis, E. A., \& Smithey, J. (2009). Beginners moving toward effective elementary science teaching. Science Education, 93(4), 745-770.

Davis, E. A., Smithey, J., \& Petish, D. (2004). Designing an online learning environment for new elementary science teachers: Supports for learning to teach. In Y. Kafai, W. Sandoval, N. Enyedy, A. Nixon, \& F. Herrera (Eds.), Proceedings of the 6th International Conference of the Learning Sciences (p. 594). Mahwah, NJ: Erlbaum.

Dietz, C., \& Davis, E. A. (2009). Preservice elementary teachers' reflection on narrative images of inquiry. Journal of Science Teacher Education, 20(3), 219-243.

Drake, C., \& Sherin, M. G. (2006). Practicing change: Curriculum adaptation and teacher narrative in the context of mathematics education reform. Curriculum Inquiry, 36(2), 153-187.

Drake, C., \& Sherin, M. G. (2009). Developing curriculum vision and trust: Changes in teachers' curriculum strategies. In J. T. Remillard, B. A. Herbel-Eisenmann, \& G. M. Lloyd (Eds.), Mathematics teachers at work: Connecting curriculum materials and classroom instruction (pp. 321-337). New York: Routledge.

Erickson, F. (1986). Qualitative methods in research on teaching. In M. C. Wittrock (Ed.), Handbook of research on teaching (pp. 119-161). New York: Macmillan.

Ericsson, K., \& Simon, H. (1993). Protocol analysis: Verbal reports as data (2nd ed.). Boston: MIT Press.

Grossman, P., \& Thompson, C. (2004). Curriculum materials: Scaffolds for new teacher learning? Seattle, WA: Center for the Study of Teaching and Policy and Center on English Learning \& Achievement (CELA).

Lincoln, Y., \& Guba, E. (1985). Naturalistic inquiry. London: Sage.

Lloyd, G. M., \& Behm, S. L. (2005). Preservice elementary teachers' analysis of mathematics instructional materials. Action in Teacher Education, 26(4), 48-62.

Miles, M., \& Huberman, A. M. (1994). Qualitative data analysis (2nd ed.). Thousand Oaks, CA: Sage.

Mulholland, J., \& Wallace, J. (2005). Growing the tree of teacher knowledge: Ten years of learning to teach elementary science. Journal of Research in Science Teaching, 42(7), 767-790.

National Center for Education Statistics (NCES). (2005). Digest of education statistics, 2007. Retrieved July 22, 2008, from http:/ / nces.ed.gov/programs/digest/d07/

National Council for the Social Studies (NCSS). (1994). Expectations of excellence: Curriculum standards for social studies. Washington, DC: Author.

National Council of Teachers of Mathematics (NCTM). (1991). Professional teaching standards for teaching mathematics. Reston, VA: Author.

National Research Council (NRC). (1996). National science education standards. Washington, DC: National Academy Press.

National Research Council (NRG). (2002). Scientific research in education. Washington, DC: National Academy Press.

Nicol, C. C., \& Crespo, S. M. (2006). Learning to teach with mathematics textbooks: How preservice teachers interpret and use curriculum materials. Educational Studies in Mathematics, 62, 331-355.

Powell, R. R. (1997). Teaching alike: A cross-case analysis of first-career and secondcareer beginning teachers' instructional convergence. Teaching and Teacher Education, 13(3), 341-356. 
Remillard, J. T. (1999). Curriculum materials in mathematics education reform: A framework for examining teachers' curriculum development. Curriculum Inquiry, 19(3), 315-342.

Remillard, J. T. (2000). Can curriculum materials support teachers' learning? Two fourth-grade teachers' use of a new mathematics text. The Elementary School Journal, 100(4), 331-350.

Remillard, J. T. (2005). Examining key concepts in research on teachers' use of mathematics curricula. Review of Educational Research, 75(2), 211-246.

Schneider, R., \& Krajcik, J. (2002). Supporting science teacher learning: The role of educative curriculum materials. Journal of Science Teacher Education, 13(3), 221245.

Schwarz, C., Gunckel, K., Smith, E., Covitt, B., Bae, M., Enfield, M., et al. (2008). Helping elementary pre-service teachers learn to use science curriculum materials for effective science teaching. Science Education, 92, 345-377.

Shulman, L. S. (1986). Those who understand: Knowledge growth in teaching. Educational Researcher, 15(2), 4-14.

Smith, D. (1999). Changing our teaching: The role of pedagogical content knowledge in elementary science. In J. Gess-Newsome \& N. Lederman (Eds.), Examining pedagogical content knowledge: The construct and its implications for science teacher education (pp. 163-198). Dordrecht, the Netherlands: Kluwer Academic Publishers.

Smith, D., \& Neale, D. (1989). The construction of subject matter knowledge in primary science teaching. Teaching and Teacher Education, 5(1), 1-20.

Valencia, S. W., Place, N. A., Martin, S. D., \& Grossman, P. L. (2006). Curriculum materials for elementary reading: Shackles and scaffolds for four beginning teachers. The Elementary School Journal, 107(1), 93-120.

Welch, W. W. (1979). Twenty years of science curriculum development: A look back. Review of Research in Education, 7, 282-308. 